\title{
Clinical Application of Quantitative Nursing for Lower Cranial Nerves Injury after Cerebellopontine Angle Tumors
}

\author{
Yanfei Zhang ${ }^{*}$, Jingxin Fu ${ }^{1}$, Qichao Chen', Yedong Wan², Ming Zhao', Longbiao Xu ${ }^{1 \#}$ \\ ${ }^{1}$ Department of Neurosurgery, Zhuji Affiliated Hospital of Shaoxing University, Zhuji People's Hospital of Zhejiang Province, \\ Zhuji, China \\ ${ }^{2}$ Department of Oncology, Second Hospital of Jilin University, Changchun, China \\ Email: ${ }^{* 18358569988 @ 163 . c o m ~}$
}

How to cite this paper: Zhang, Y.F., Fu, J.X., Chen, Q.C., Wan, Y.D., Zhao, M. and $\mathrm{Xu}$, L.B. (2021) Clinical Application of Quantitative Nursing for Lower Cranial Nerves Injury after Cerebellopontine Angle Tumors. International Journal of Clinical Medicine, 12, 190-201.

https://doi.org/10.4236/ijcm.2021.125018

Received: April 16, 2021

Accepted: May 21, 2021

Published: May 24, 2021

Copyright $\odot 2021$ by author(s) and Scientific Research Publishing Inc. This work is licensed under the Creative Commons Attribution International License (CC BY 4.0).

http://creativecommons.org/licenses/by/4.0/

\section{(c) (i) Open Access}

\begin{abstract}
Objective: To retrospectively analyze the clinical utility of quantitative nursing measures of 10 cases of lower cranial nerves injury after cerebellopontine angle tumors surgery to provide the experience for improving the recovery rate and living quality of these patients. Methods: The clinical data of 10 cases of lower cranial nerves injury after cerebellopontine angle tumors surgery was analyzed. For problems such as dysphagia and dyspnea of these patients, the nursing care focused on strict monitoring, timely oxygen inhalation nursing, posture nursing, ventilator nursing, swallowing function training, etc. Results: After received quantitative care, 10 patients with lower cranial nerves injury after cerebellopontine angle tumors surgery were recovered well, and their symptoms such as dysphagia and dyspnea were gradually improved and safely discharged. Conclusion: Lower cranial nerves injury is one of the serious complications after removal of cerebellopontine angle tumors, which impacts the life and health of patients. Caregivers should accurately understand and analyze the symptoms, and quantitative and targeted nursing measures for posterior cranial nerves injury are helpful in the postoperative rehabilitation of patients and improve their living quality.
\end{abstract}

\section{Keywords}

Quantitative Nursing, Cerebellopontine Angle Tumors, Lower Cranial Nerves Injury

\section{Introduction}

Cerebellopontine angle (CPA) tumors, of which vestibular schwannoma (75\% -

*Authors contributed equally.

${ }^{\#}$ Corresponding author. 
$85 \%)$, meningioma (10\% - 15\%), and epidermoid tumor $(7 \%-8 \%)$ are the most common neoplasms, make up about 5\% - 10\% of all intracranial tumors. Most patients with this disease show hearing impairment and facial nerve dysfunction [1]. And the main treatment measures for neoplasms in this area are observation, radiotherapy, and surgery [2]. At present, with the development of surgical technology, the surgical treatment of CPA tumors based on micromanipulation has been more and more valuable. However, postoperative complications such as cerebrospinal fluid leakage, meningitis, and lower cranial nerves (LCNs) injury are mainly caused by accidental injury during electrocoagulation or traction during separation, and characterized by dysphagia, dyspnea, and other symptoms [3] are still impossible to neglect. At present, general health education and routine nursing care measures administered by caregivers to patients after CPA tumors surgery, to some extent, contribute to postoperative recovery. But the lack of a specific and individualized quantification protocol for the impairment of LCNs leads to poor patients' compliance and low quality of care, which makes it impossible to achieve the desired outcome. Therefore, for patients complicated with LCNs injury, taking corresponding quantitative nursing measures according to the severity of symptoms should be considered an effective approach to treating LCNs injury after CPA tumors surgery. Reviewing 121 patients treated in the Department of Neurosurgery of our hospital with CPA tumors from January 2016 to December 2020, there were 10 patients complicated by LCNs injury postoperatively. We found that they all achieved satisfactory results with good prognoses after the application of formulated quantitative nursing strategy. Here it reports as follows.

\section{Ethical Review}

This case report was approved by the clinical ethics committee of the Zhuji Affiliated Hospital of Shaoxing University. Informed consent had been acquired in writing.

\section{Materials and Methods}

\subsection{General Information}

In our hospital from 2016 to 2020, 10 cases of cerebellopontine angle tumor with postoperative cranial nerves injury were seriously selected according to the inclusion criteria: 1) preoperative MRI and contrast-enhanced MRI showed that the cerebellopontine angle area was occupied; 2) no LCNs injury before an operation, such as dysphagia, hoarseness, drinking cough, dyspnea; 3) LCNs injury after operation; 4) age 20 - 70 years old; 5) no other severe visceral diseases. There were 4 males and 6 females, aged from 29 to 70 years old. Suboccipital retrosigmoid sinus approach was adopted in operation, with the tumor resected completely. Postoperative pathology demonstrated vestibular schwannoma in 7 cases, meningioma in 2 cases, and hyalinizing hemangioma in 1 case. The basic information of each patient (Table 1), enhanced MRI images (Figure 1) and 
Table 1. Summary of patients' basic condition and clinical features.

\begin{tabular}{|c|c|c|c|c|c|c|}
\hline Case & Age (years) & Gender & Chief complaint & $\begin{array}{l}\text { Lesion's } \\
\text { location and size }\end{array}$ & Pathology & $\begin{array}{l}\text { Symptoms } \\
\text { after surgery }\end{array}$ \\
\hline 1 & 29 & Male & $\begin{array}{l}\text { Right ear progressive hearing } \\
\text { lose and tinnitus for } 2 \text { years }\end{array}$ & $\begin{array}{l}\text { Right, } \\
15 \times 15 \mathrm{~mm}\end{array}$ & $\begin{array}{c}\text { vestibular } \\
\text { schwannoma }\end{array}$ & Dysphagia (II) \\
\hline 2 & 50 & Male & Left ear tinnitus for 7 months & $\begin{array}{c}\text { Left, } \\
26 \times 24 \mathrm{~mm}\end{array}$ & $\begin{array}{c}\text { vestibular } \\
\text { schwannoma }\end{array}$ & Dysphagia (III) \\
\hline 4 & 52 & Female & Right ear tinnitus for 1 month & $\begin{array}{l}\text { Right, } \\
19 \times 13 \mathrm{~mm}\end{array}$ & $\begin{array}{l}\text { hyalinizing } \\
\text { hemangioma }\end{array}$ & Dysphagia (IV) \\
\hline 5 & 70 & Male & $\begin{array}{l}\text { Vertigo and left ear hearing } \\
\text { loss for } 2 \text { months }\end{array}$ & $\begin{array}{c}\text { Left, } \\
25 \times 21 \mathrm{~mm}\end{array}$ & $\begin{array}{c}\text { vestibular } \\
\text { schwannoma }\end{array}$ & $\begin{array}{c}\text { Dysphagia }(\mathrm{V}), \\
\text { dyspnea }\end{array}$ \\
\hline 7 & 61 & Female & Left ear tinnitus for 3 months & $\begin{array}{l}\text { Left, } \\
13 \times 15 \mathrm{~mm}\end{array}$ & $\begin{array}{c}\text { vestibular } \\
\text { schwannoma }\end{array}$ & Dysphagia (III) \\
\hline 8 & 37 & Male & Left ear tinnitus for 3 years & $\begin{array}{c}\text { Left, } \\
17 \times 36 \mathrm{~mm}\end{array}$ & $\begin{array}{c}\text { vestibular } \\
\text { schwannoma }\end{array}$ & Dysphagia (II) \\
\hline 9 & 63 & Female & Right ear hearing loss for 8 years & $\begin{array}{l}\text { Right, } \\
4.2 \times 6.2 \mathrm{~mm}\end{array}$ & $\begin{array}{c}\text { vestibular } \\
\text { schwannoma }\end{array}$ & $\begin{array}{c}\text { Dysphagia (IV), } \\
\text { dyspnea }\end{array}$ \\
\hline 10 & 47 & Female & $\begin{array}{l}\text { Dizziness and headache } \\
\text { for } 2 \text { months }\end{array}$ & $\begin{array}{l}\text { Right, } \\
17 \times 15 \mathrm{~mm}\end{array}$ & meningioma & Dysphagia (III) \\
\hline
\end{tabular}
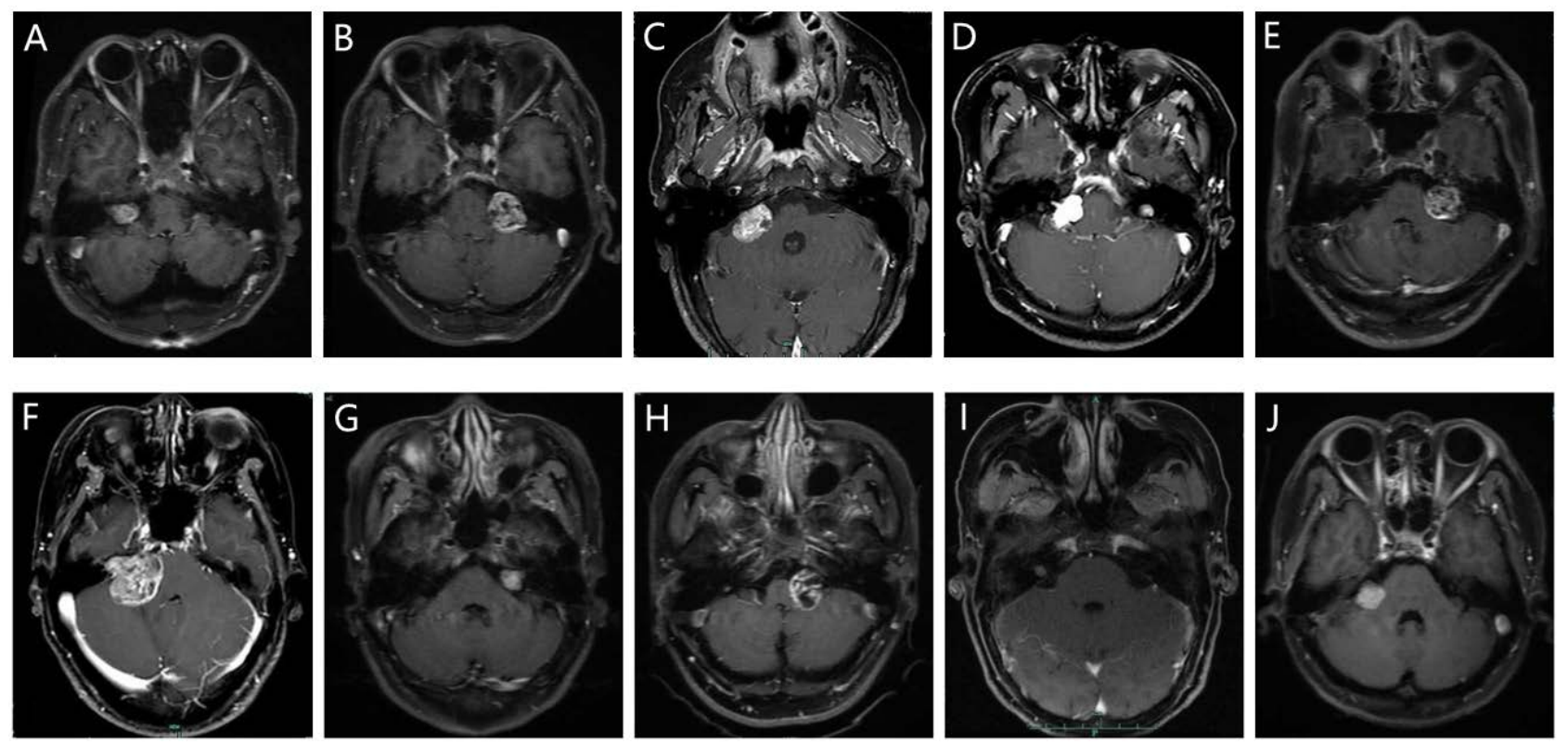

Figure 1. Contrast enhanced MRI of the patients.

characteristics of the selected patients (Table 2) are as follows:

\subsection{Methods}

\subsubsection{Operative Procedures}

After general anesthesia, patients underwent tumor resection with a posterior 
Table 2. Patients' characteristics $(\mathrm{n}=10)$.

\begin{tabular}{ll}
\hline & Number \\
\hline Age (years) & 2 \\
$<40$ & 4 \\
$40-60$ & 4 \\
$\geq 60$ & \\
Gender & 4 \\
Male & 6 \\
Female & \\
Pathology & 7 \\
Vestibular schwannoma & 2 \\
Meningioma & 1 \\
Hyalinizing hemangioma & \\
Dysphagia & 2 \\
Level II & 4 \\
Level III & 3 \\
Level IV & 1 \\
Level V & 4 \\
Dyspnea & 3 \\
\hline
\end{tabular}

approach to the suboccipital sigmoid sinus in the lateral decubitus position. The dura was opened intraoperatively with cross scissors, allowing CSF to slowly leak out of the cistern. After confirming the course of facial and trigeminal nerve and tumor surface vessels under low cranial pressure, the tumor was isolated, and care was taken during this procedure to prevent brain stem injury. Upon completion, the wound was hemostatic, irrigated, and sutured layer by layer or using titanium mesh for tension-reducing sutures in patients with high incision tension, combined with sterile bandaging of the head.

\subsubsection{LCNs Injury Assessment}

Deglutition disorders evaluation was performed by the water swallow test (WST). Patients took a sitting position and drank $30 \mathrm{ml}$ of $37^{\circ} \mathrm{C}-40^{\circ} \mathrm{C}$ water with personal habits, divided into 5 levels according to the following criteria: drinking water once successfully within $5 \mathrm{~s}$ (I); swallowing more than twice to drink completely within $5 \mathrm{~s}$ (II); drinking water once but coughing or choking (III); drinking water more than twice with coughing or choking (IV); drinking interruptedly and incompletely due to repeat coughing or choking (V). Respiratory function evaluation was performed by observing patients' respiratory rate (RR), blood oxygen saturation $\left(\mathrm{SpO}_{2}\right)$, and lip color.

\subsubsection{Quantitative Nursing Measures}

1) Position nursing. Postoperatively, patients' body were in a dorsal elevated position at a $30^{\circ}$ angle to the horizontal plane to reduce the intracranial blood 
flow and decrease the cranial pressure. Meanwhile, biased their heads to one side to prevent glossoptosis and thus breathing difficulties. In patients with large vestibular schwannoma, a healthy lateral position was taken because a large cavity would be left after removal of the tumor in the pontocerebellar region, preventing cranial collapse. Moving the head was rigorously prohibited in patients and their families for $24 \mathrm{~h}$ postoperatively in order not to compress other tissues such as the brainstem and thus serious consequences. The sandbag was put on one side of patients' heads within 1 week postoperatively for a brake. Patients were instructed to rest strictly in bed until full recovery of activity function.

2) Psychological nursing. Negative emotions such as anxiety and depression were often found in patients after tumor or cranial surgery. Caregivers should actively communicate with them to understand their psychological appeal, timely comfort them, and encourage patients to cooperate with postoperative rehabilitation treatment. In addition to the necessary contact with patients required by daily nursing, nurses should take the initiative to talk with patients and their families at least once a day to understand the pressure and difficulties faced by patients, and help them analyze these challenges and provide proper solutions; Encourage patients to record their psychological activities and emotional changes every day, discuss the sources of stress with the consent of patients, and help them ease their emotional problems.

3) Vital signs monitoring. Postoperatively, patients consciousness were observed, and the pupillary light reflex was examined for the presence and sensitivity. Unilateral absence of light reflexes or unequal size of bilateral pupils indicated cerebral hernia; the absence of bilateral light reflexes suggested that patients were in critical condition and required prompt rescue. Nurses should timely measure their temperature and promptly notice the increase in temperature caused by postoperative fever or intracranial infection. If the temperature is excessive, a wet towel should be used as a cold compress on the forehead for physical cooling. The bedside multifunctional monitor was used to real-time measure patients' blood pressure, heart rate, electrocardiogram, and oxygen saturation. Nurses ought to pay attention to the risk of hypotension caused by mannitol dehydration, disturbance of hydroelectrolyte balance, and so on in patients with head trauma, so the urine volume, blood pressure, and intracranial pressure must be kept in the normal range.

4) Respiratory function nursing. Four patients with respiratory dysfunction were found in this study. Postoperatively, their heads were placed on one side to prevent dyspnea caused by glossoptosis. Patients with LCNs injury had poor pharyngeal reflex, who often failed to clear food that had remained in the pharyngeal wall in a timely manner, and care needed to be taken to clean their mouths on time and prevent viscous materials such as food residue or sputum from obstructing the trachea. Tongue retropulsion of LCNs injury and aspiration pneumonia from aspiration or mechanical ventilation could lead to hypoventilation and alveolar diffusion dysfunction, and severe cases to II breath prostrate with $\mathrm{SpO}_{2} \leq 90 \%$, cyanosis of the lips and lower extremities, dysphoria, 
and confusion. A bedside multifunctional monitor was used to monitor RR and $\mathrm{SpO}_{2}$ of patients while observing the color of their lips to determine the presence of hypoxia. When a critical situation such as respiratory distress occurred, a ventilator or invasive tracheal intubation was adopted in order to guarantee the vital signs of patients. When a ventilator was used, caregivers should lay emphasis on the disinfection of the tube and regular testing of its patency, and extubate the tube when patienta regain spontaneous respiratory function. When tracheostomy was used, extubation was indicated when their respiratory function and cough reflex recovered, known as the protocol of "Early Cut and Early Extubate", to help them regain spontaneous breathing ability.

5) Swallowing function nursing. In this study, 10 patients had dysphagia symptoms such as hoarseness or choking cough in varying degrees. According to the water swallow test (WST), there were 2 patients with level II, 4 patients with level III, 3 patients with level IV and 1 patient with level V. Dysphagia interventions could be divided into two forms, a compensatory approach and a rehabilitation approach [4]. Quantitative program should be developed based on the degree of dysphagia in different patients. Patients with swallowing test level I (5s or more) or level II or III were mild patients, a total of 6 cases, and the compensatory approaches started within 1 day after the operation. 1) Dietary modifications: Patients were provided with corresponding food based on the International Dysphagia Diet Standardisation Initiative (IDDSI) framework (Figure 2), and the difficulty gradient of swallowing food was increased in the process, so that patients' swallowing function can be gradually normalized. Researches have shown that foods/drinks in IDDSI III-IV are located in the solid-liquid coincidence section, which are best for patients with dysphagia. Foods in this interval

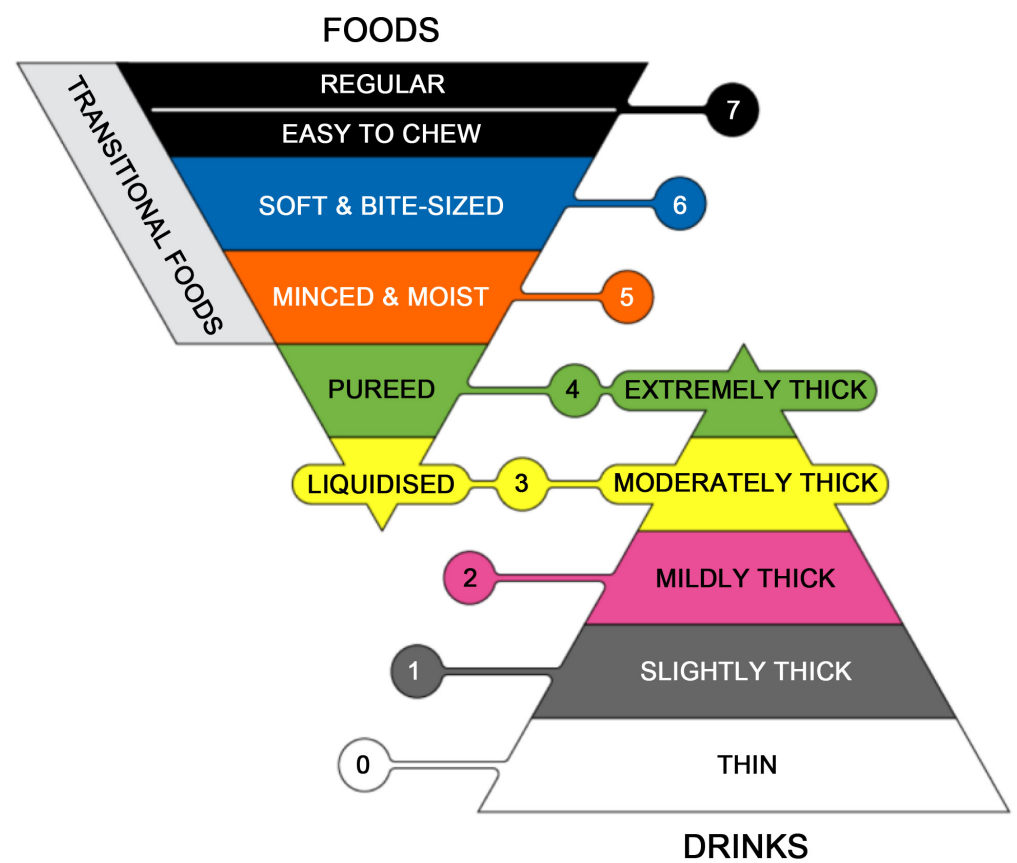

Figure 2. The dietary texture levels of IDDSI (iddsi.org/framework). 
range decrease firmness of solid foods to facilitate chewing and swallowing, while also increasing the consistency of liquids to avoid the risk of choking [5]. Patients were given extremely thick fluids or pureed food (determined by the amount of liquid remaining after $10 \mathrm{~s}$ in a $10 \mathrm{ml}$ syringe tube) within 2 weeks after surgery to start training, and gradually switch to pasty solid but digestible food and thin liquids to increase the difficulty of swallowing. The thickness of the foods/drinks should be controlled to the extent that it is unlikely to remain on mucous membranes, including thick milk, pureed vegetables, crushed meat, and so on. Excessive fiber-containing foods such as asparagus and eggplants should be avoided to prevent patients from aspiration due to incomplete chewing, foods mixed with solid and liquid such as watermelon should be avoided to prevent patients from bucking or aspiration due to poor liquid control, and overly crispy foods should be avoided to prevent debris from obstructing the esophagus [6] [7]. In addition, the amount of food should be adapted to trigger the pharyngeal reflex, with the dose starting at 3 to $4 \mathrm{ml}$ once and gradually increasing to about $20 \mathrm{ml} .2$ ) Postural training: Patients were seated and fed with the body tilted forward at $20^{\circ}[6]$ [8], so that the food could enter smoothly and stimulate the swallowing reflex, preventing aspiration during eating. 3) Assisted feeding: The spoon was pressed against the base of tongue during eating to stimulate swallowing movements, and verbal encouragement was given to create a proper atmosphere for feeding, while patients were instructed to adjust the head position on their own to aid in swallowing the food. Patients with swallowing test level IV-V were severe patients, a total of 4 cases, and they were fed with the nasogastric tube within 2 days postoperatively, and the two forms of swallowing function training started combinedly 2 days later. The methods for compensation were described above. The purpose of rehabilitative training was to prevent muscle disuse atrophy and enhance the motor abilities and coordination of the oral, facial, lingual, and jaw muscle groups [9] [10]. Patients trained under the nurse's demonstration and instruction for 15 min every approach twice a day. a) Tongue movement: Patients were instructed to extend their tongues as far forward, right, and left as possible and kept the tongue base elevated. The tongue was applied resistance with a tongue depressor during extension, and patients were instructed to counteract bilateral buccinator muscles for resistance exercises. At ordinary times, Patients could use the tongue to sweep the gums up and down, right and left, and make a " $K$ " sound for exercising. b) Lip movement: It consisted of closing the lips, pouting, and smiling. Training was conducted by applying resistance through separating patients' lips with double fingers while closing lips, pulling lips corners externally while pouting, and pulling down lips corners while smiling. c) Temperature stimulation: The tongue spatula was placed in ice water for half a minute, and after removal, it repeatedly stimulated the deutomala, soft palate, pillars faucial, root of tongue, and retropharyngeal wall of patients to induce the pharynx reflex to achieve the training effect. 4) Glottic training: Patients were instructed to speak of "ah" loud to close the glot- 
tis; or to inhale vigorously, swallow saliva while holding their breath, and then exhale and cough. Recovery of glottic function was achieved through the supraglottic swallowing training described above.

\section{Result}

Among the 10 patients in this study, there were 10 patients with dysphagia. After one month of compensatory or rehabilitation swallowing function nursing according to individual conditions, both mild and severe patients' swallowing function recovered well, and their performance in WST improved differently (Table 3). There were 4 of the 10 patients with dyspnea, including 3 patients treated with ventilator and 1 patient treated with endotracheal intubation, who showed progressive improvement in respiratory function after nursing care, as indicated by return of spontaneous breathing capacity with $\mathrm{SpO}_{2} \geq 90 \%$. After targeted nursing, all patients had stable vital signs and good mental status, and finally met the rehabilitation criteria and were successfully discharged.

Table 3. Nursing measures and outcomes for patients with dysphagia.

\begin{tabular}{|c|c|c|c|c|}
\hline Case & $\begin{array}{l}\text { Dysphagia level } \\
\text { (before nursing) }\end{array}$ & $\begin{array}{l}\text { Dysphagia } \\
\text { severity }\end{array}$ & Nursing approaches & $\begin{array}{l}\text { Dysphagia level } \\
\text { (1 month later) }\end{array}$ \\
\hline 1 & II & Mild & $\begin{array}{l}\text { Compensatory approaches started within } 1 \text { day } \\
\text { after surgery }\end{array}$ & I \\
\hline 2 & III & Mild & $\begin{array}{l}\text { Compensatory approaches started within } 1 \text { day } \\
\text { after surgery }\end{array}$ & I \\
\hline 3 & IV & Severe & $\begin{array}{l}\text { Nasogastric tube feeding started within } 2 \text { days after surgery, } \\
\text { and compensatory approaches combined with rehabilitative } \\
\text { approaches started } 2 \text { days later }\end{array}$ & II \\
\hline 4 & IV & Severe & $\begin{array}{l}\text { Nasogastric tube feeding started within } 2 \text { days after surgery, } \\
\text { and compensatory approaches combined with rehabilitative } \\
\text { approaches started } 2 \text { days later }\end{array}$ & I \\
\hline 5 & $\mathrm{~V}$ & Severe & $\begin{array}{l}\text { Nasogastric tube feeding started within } 2 \text { days after surgery, } \\
\text { and compensatory approaches combined with rehabilitative } \\
\text { approaches started } 2 \text { days later }\end{array}$ & III \\
\hline 6 & III & Mild & $\begin{array}{l}\text { Compensatory approaches started within } 1 \text { day } \\
\text { after surgery }\end{array}$ & II \\
\hline 7 & III & Mild & $\begin{array}{l}\text { Compensatory approaches started within } 1 \text { day } \\
\text { after surgery }\end{array}$ & II \\
\hline 8 & II & Mild & $\begin{array}{l}\text { Compensatory approaches started within } 1 \text { day } \\
\text { after surgery }\end{array}$ & I \\
\hline 9 & IV & Severe & $\begin{array}{l}\text { Nasogastric tube feeding started within } 2 \text { days after surgery, } \\
\text { and compensatory approaches combined with rehabilitative } \\
\text { approaches started } 2 \text { days later }\end{array}$ & II \\
\hline 10 & III & Mild & $\begin{array}{l}\text { Compensatory approaches started within } 1 \text { day } \\
\text { after surgery }\end{array}$ & I \\
\hline
\end{tabular}




\section{Discussion}

The cerebellopontine angle region is located in the deep part of the cranial cavity, where the surrounding anatomical structures are complex. The operative mortality of CPA has been significantly reduced owing to the development of microsurgery [11]. The suboccipital approach is commonly used for the resection of CPA tumors [12]. Lower cranial nerves (LCNs) are composed of the glossopharyngeal nerve, vagus nerve, accessory nerve, and hypoglossal nerve. It was once thought that the odds of LCNs being damaged intraoperatively were low unless the tumor was large [13] [14]. But recent studies have shown that although the injury of LCNs is relatively rare in patients with cerebellopontine angle tumors, the incidence of LCNs injury can reach $8.4 \%$ after operations in those patients. Most of them may have swallowing dysfunction (including dysphagia and choking cough), dyspnea, or hoarseness, and these complications may delay the postoperative recovery, decrease the qualities of life of patients, and even cause death [3] [15] [16] [17] [18]. However, because symptoms of cranial nerve injury such as dysphagia are predominantly seen in the elderly, acute stroke, and critically ill patients, systematic nursing interventions are currently focused on the stroke population [19]. Therefore, patients with LCNs injury after cerebellopontine angle tumors surgery need a set of systematic quantitative nursing methods, and the diversified performances also make many aspects of the nursing processes need to be paid more attention to. The specific analysis is as follows: 1) Dysphagia is one of the commonest clinical manifestations of glossopharynx or vagal nerve injury [4] [17], which often exposes patients to the risk of food aspiration and asphyxia. Management of dysphagia includes compensatory approaches consisting of appropriate position, gradient diet and auxiliary feeding adjustment, and rehabilitative training consisting of orolingual pharyngeal muscle group training in strength and resistance and pharyngeal reflex stimulation [4] [20] [21]. Recent studies have shown that oral feeding according to food structure adjustments better improves swallowing function than tube feeding, intravenous nutrition while meeting patients' dietary needs [22]. Because of the disunity of standards of food classification across countries, the international dietary classification IDDSI was used in this study to meet the needs of dysphagia patients of different ages and grades. In our study, 6 patients with mild dysphagia (water swallow test $\leq$ level III) and 4 patients with severe dysphagia (water swallow test $\geq$ level IV) all achieved good results after quantitative care. It is suggested that adjustment of diet by IDDSI and quantitative swallowing muscle function training should be emphasized in nursing of patients with LCNs injury after CPA tumors resection. 2) Dyspnea and wheezing after LCNs injury are often caused by aspiration pneumonia secondary to dysphagia, vocal cord paralysis due to vagus nerve injury, and tongue base descent as a result of glossopharyngeal nerve injury [16] [23]. Nursing work should include regular cleaning of patients' mouth, observation of lip color, and monitoring of respiratory rate, blood oxygen saturation and oxygen supply status in 
real-time. Simultaneously, it is advisable to tilt patients heads to one side to prevent the anteroposterior wallowing tongue base due to nerve paralysis. In an emergency, tracheal intubation should be established in advance, and after tracheal intubation, we should pay attention to the prevention of ventilator-associated pneumonia (VAP) via rational nursing care. In this study, 4 patients with dyspnea recovered well after the above special care. 3) Patients with LCNs injury show anxiety and depression due to the pressure of tumors, brain operations, and complicated LCNs injury, so giving positive psychological nursing to those after the operation is conducive to helping patients recover.

\section{Conclusion}

Above all, lower cranial nerves injury is one of the serious complications after resection of cerebellopontine angle tumors, which affects prognosis and the life and health of patients. Caregivers should clearly understand the characteristics of the tumors' location, and accurately analyze the postoperative complications. Implementation of quantitative nursing interventions is able to minimize the adverse outcomes secondary to postoperative lower cranial nerves injury, and will allow patients to recover as soon as possible.

\section{Fund Projects}

This study was funded by the Medical and health technology project of Zhejiang Province (2020RY081), Science and technology bureau project of Shaoxing (2018C30150), Clinical research fund of Zhejiang Medical Association (2019ZYC-A52).

\section{Authors' Contributions}

Yanfei Zhang and Jingxin Fu contributed equally. As the main writers of this study, they completed the data curation and formal analysis and wrote the main part of the manuscript. Qichao Chen, Yedong Wan, Ming Zhao took part in the analysis and collation of literature. Longbiao $\mathrm{Xu}$, as the designer and director of the project, guided the report writing. All authors read and agree to the final text.

\section{Conflicts of Interest}

The authors declare no conflicts of interest regarding the publication of this paper.

\section{References}

[1] Samii, M. and Gerganov, V.M. (2012) Tumors of the Cerebellopontine Angle. In: Handbook of Clinical Neurology, Vol. 105, Elsevier, Amsterdam, 633-639. https://doi.org/10.1016/B978-0-444-53502-3.00013-6

[2] Quesnel, A.M. and Santos, F. (2018) Evaluation and Management of Facial Nerve Schwannoma. Otolaryngologic Clinics of North America, 51, 1179-1192. https://doi.org/10.1016/j.otc.2018.07.013 
[3] Policeni, B.A. and Smoker, W.R.K. (2008) Pathologic Conditions of the Lower Cranial Nerves IX, X, XI, and XII. Neuroimaging Clinics of North America, 18, 347. https://doi.org/10.1016/j.nic.2007.12.012

[4] Lancaster, J. (2015) Dysphagia: Its Nature, Assessment and Management. British Journal of Community Nursing, 20, S28-S32. https://doi.org/10.12968/bjcn.2015.20.Sup6a.S28

[5] Cichero, J.A.Y., Lam, P., Steele, C.M., Hanson, B., Chen, J., Dantas, R.O., et al. (2017) Development of International Terminology and Definitions for Texture-Modified Foods and Thickened Fluids Used in Dysphagia Management: The IDDSI Framework. Dysphagia, 32, 293-314. https://doi.org/10.1007/s00455-016-9758-y

[6] Wirth, R., Dziewas, R., Beck, A.M., Clave, P., Hamdy, S., Heppner, H.J., et al. (2016) Oropharyngeal Dysphagia in Older Persons-From Pathophysiology to Adequate Intervention: A Review and Summary of an International Expert Meeting. Clinical Interventions in Aging, 11, 189-208. https://doi.org/10.2147/CIA.S97481

[7] Steele, C.M., Alsanei, W.A., Ayanikalath, S., Barbon, C.E.A., Chen, J., Cichero, J.A.Y., et al. (2015) The Influence of Food Texture and Liquid Consistency Modification on Swallowing Physiology and Function: A Systematic Review. Dysphagia, 30, 2-26. https://doi.org/10.1007/s00455-014-9578-x

[8] Saitoh, E. (2008) Dysphagia Rehabilitation. Rinsho shinkeigaku = Clinical Neurology, 48, 875-879. https://doi.org/10.5692/clinicalneurol.48.875

[9] Kim, H.D., Choi, J.B., Yoo, S.J., Chang, M.Y., Lee, S.W. and Park, J.S. (2017) Tongue-to-Palate Resistance Training Improves Tongue Strength and Oropharyngeal Swallowing Function in Subacute Stroke Survivors with Dysphagia. Journal of Oral Rehabilitation, 44, 59-64. https://doi.org/10.1111/joor.12461

[10] Hagglund, P., Hagg, M., Wester, P. and Jaghagen, E.L. (2019) Effects of Oral Neuromuscular Training on Swallowing Dysfunction among Older People in Intermediate Care-A Cluster Randomised, Controlled Trial. Age and Ageing, 48, 533-540. https://doi.org/10.1093/ageing/afz042

[11] Betka, J., Zverina, E., Balogova, Z., Profant, O., Skrivan, J., Kraus, J., et al. (2014) Complications of Microsurgery of Vestibular Schwannoma. Biomed Research International, 2014, Article ID: 315952. https://doi.org/10.1155/2014/315952

[12] Huang, M.Y. and Vermeulen, S. (2003) Clinical Perspectives Regarding Patients with Internal Auditory Canal or Cerebellopontine Angle Lesions: Surgical and Radiation Oncology Perspectives. Seminars in Ultrasound CT and MRI, 24, 124-132. https://doi.org/10.1016/S0887-2171(03)90034-5

[13] Samii, M. and Matthies, C. (1997) Management of 1000 Vestibular Schwannomas (Acoustic Neuromas): Surgical Management and Results with an Emphasis on Complications and How to Avoid Them. Neurosurgery, 40, 11-21. https://doi.org/10.1097/00006123-199701000-00002

[14] Lanman, T.H., Brackmann, D.E., Hitselberger, W.E. and Subin, B. (1999) Report of 190 Consecutive Cases of Large Acoustic Tumors (Vestibular Schwannoma) Removed via the Translabyrinthine Approach. Journal of Neurosurgery, 90, 617-623. https://doi.org/10.3171/jns.1999.90.4.0617

[15] Yamakami, I., Ito, S. and Higuchi, Y. (2014) Retrosigmoid Removal of Small Acoustic Neuroma: Curative Tumor Removal with Preservation of Function. Journal of Neurosurgery, 121, 554-563. https://doi.org/10.3171/2014.6.JNS132471

[16] Gutierrez, S., Warner, T., McCormack, E., Werner, C., Mathkour, M., Iwanaga, J., et al. (2020) Lower Cranial Nerve Syndromes: A Review. Neurosurgical Review, 44, 
1345-1355. https://doi.org/10.1007/s10143-020-01344-w

[17] Ward, B.K., Francis, H.W., Best, S.R., Starmer, H.M., Akst, L.M. and Gourin, C.G. (2012) National Prevalence and Impact of Perioperative Vagus Nerve Injury in Vestibular Schwannoma. Laryngoscope, 122, 2824-2831.

https://doi.org/10.1002/lary.23605

[18] Best, S.R., Starmer, H.M., Agrawal, Y., Ward, B.K., Hillel, A.T., Chien, W.W., et al. (2012) Risk Factors for Vagal Palsy Following Cerebellopontine Angle Surgery. Otolaryngology_Head and Neck Surgery, 147, 364-368.

https://doi.org/10.1177/0194599812442042

[19] Duncan, S., Mc Gaughey, J., Fallis, R., McAuley, D.F., Walshe, M. and Blackwood, B. (2019) Interventions for Oropharyngeal Dysphagia in Acute and Critical Care: A Protocol for a Systematic Review and Meta-Analysis. Systematic Reviews, 8, 283. https://doi.org/10.1186/s13643-019-1196-0

[20] Fukuoka, T., Ono, T., Hori, K., Tamine, K.-I., Nozaki, S., Shimada, K., et al. (2013) Effect of the Effortful Swallow and the Mendelsohn Maneuver on Tongue Pressure Production against the Hard Palate. Dysphagia, 28, 539-547.

https://doi.org/10.1007/s00455-013-9464-y

[21] Robbins, J., Kays, S.A., Gangnon, R.E., Hind, J.A., Hewitt, A.L., Gentry, L.R., et al. (2007) The Effects of Lingual Exercise in Stroke Patients with Dysphagia. Archives of Physical Medicine and Rehabilitation, 88, 150-158. https://doi.org/10.1016/j.apmr.2006.11.002

[22] Sun, Q., Su, Y., Xiang, Y.X., Jia, X.L., Liu, J., He, X.L., et al. (2018) Effect of Food Improvement on the Retention Time of Nasogastric Tube in Stroke Patients with Dysphagia. Chinese Journal of Practical Nursing, 34, 742-745.

[23] Patel, H.C., Bouamra, O., Woodford, M., King, A.T., Yates, D.W., Lecky, F.E., et al. (2005) Trends in Head Injury Outcome from 1989 to 2003 and the Effect of Neurosurgical Care: An Observational Study. The Lancet, 366, 1538-1544. https://doi.org/10.1016/S0140-6736(05)67626-X 